Research Article

\title{
The Inner Life of An Experienced Meditator: From Shopping Lists to Awakening
}

\author{
Peter M. Forster ${ }^{1}$ \\ University of Worcester
}

${ }^{1}$ University of Worcester, Henwick Grove, Worcester, WR2 6AJ, United Kingdom. E-mail: p.m.forster.76@cantab.net

Corresponding author: Peter Forster, Ph.D.

(Cantab)

E-mail:

p.m.forster.76@cantab.net

eISSN: 2458-9675

Received: 27.11.2020

Revision: 01.02.2021

Accepted: 09.02.2021

CCopyright 2021

by Author(s)

\begin{abstract}
This article addresses the little-studied area of the subjective experience of meditation through the analysis of the daily meditation diary of an experienced meditator over 2 months during the covid-19 lockdown in England in early 2020. The participant, who began meditating over 40 years ago, practised an open monitoring style of meditation for 90 minutes every day followed by 30 -minutes of reflecting and writing notes on the experience. The meditation time included 60 minutes of ambient sounds and 30 minutes of binaural audio. The main and overarching themes in these diaries were identified by thematic analysis. Overarching themes were 'What is meditation' and 'Something feels different! Changes in sensations or feelings while meditating'. One stand-alone theme was identified, 'Unusual or altered states of consciousness'. The Buddhist concept of jhanas may provide a framework for understanding such experiences. These themes were discussed for the insights they provide into the meditation process. Keywords:

Meditation, Meditation diary, Subjective experience, Phenomenology, Unusual or altered states of consciousness, Ethnography
\end{abstract}


Although there have been many quantitative studies of the effects of meditation, there are relatively few of the subjective experiences of meditators (Ekici, Garip \& Van Gordon, 2020; Kjellgren \& Taylor, 2008). Of those studies that have attempted this, the main approach has been through post-meditation questionnaires (Thomas $\&$ Cohen, 2014). A narrative account of one person's life experiences while engaging in Vipassana meditation over a two-year period is given by Walsh (1977) and a qualitative study of the experiences of experienced and inexperienced Zazen meditators was carried out by Kjellgren and Taylor (2008). Isbel, Sysak and Summers (2020) used meditation diaries to study the development of meditation skills over an eight-week period. One of the few larger-scale studies of meditation experience was of 60 Buddhist meditators, of unspecified experience, plus a small group of 'expert' meditators (Lindahl, Fisher, Cooper, Rosen \& Britton, 2017). The participants in that study were interviewed about the broad experience of their meditation practice using semi-structured interviews. No attempt was made to conduct the interviews closely in time following a meditation. Thematic analysis of the interview data yielded seven broad domains of response: cognitive, perceptual, affective, somatic, conative, sense of self, and social.

The present study aims to fill a gap in the literature on meditation by studying the subjective experiences of one experienced meditator through the analysis of the meditation diaries completed immediately after each daily meditation session. These diaries were of the specific experiences during each, individual meditation.

This study can also be seen as cultural autoethnography, a study of the cultural practices of those who meditate, through the observations of a long-standing member of that culture. It presents a window into this culture though systematic recordings of meditation practice. It is ethnography as a way of seeing that is consistent with the title of the review essay, "If Somebody's with Something Every Day They've Gotta Learn Something - Or They're Just Out to Lunch": The Dialectics of Ethnography as a Way of Being' (Roth, 2003). The forms of autoethnography vary from those that place most emphasis on others to those that place most emphasis on self (Ellis, Adams \& Bochner, 2011). The emphasis in this study is on personal narrative and invites readers to use this study to reflect on and understand their own world.

The study is consistent with, and sympathetic to, the aims of the Emergent Phenomenological Research Consortium (EPRC) (n.d.), in that it refers to experiences that can arise during meditation, contemplation and similar practices, and it is phenomenological in drawing on subjective, first person experiences. The EPRC seeks to expand the number of such studies to better understand this important aspect of human experience. And like the EPRC, this paper seeks to add to knowledge and possible applications of practice to a greater extent than the development of theory. 
The broader intention is to help less experienced meditators gain some idea of where meditation might lead them. This study is based on the idea that people who have not meditated before, or who have little experience of meditation, want to know about the subjective experiences that occur while meditating. They may well have been attracted to meditation by hearing that it helps reduce stress or increases wellbeing and so on, but the inner experience is also important to them. So this study was designed to reveal something of the inner experience of a meditator's usual daily practice over a two-month period. Why two months? Many studies of the effects of meditation on health and well-being etc. have been done with participants on popular eight-week courses such as Mindfulness-Based Stress Reduction (MBSR) and Mindfulness-Based Cognitive Therapy (MBCT). Two months is long enough to reveal effects in those studies and also to give an idea of the range of experiences that are typical among regular meditators.

Finally, a more specific context and aim for this study is of the author living alone, with limited possibilities for leaving the home because of the first government-imposed lockdown during the covid-19 pandemic in 2020 in England. In other words, it is a study that one person could do to make the most of the pandemic lockdown, and it could help people interested in starting to meditate, while contributing to my own well-being and the feeling of doing something useful, meditation being a practice that led to greater wellbeing in one early study during the pandemic (Lades, Laffan, Daly \& Delaney, 2020).

There are many types of meditation, often broadly divided into three types (Lippelt, Hommel \& Colzato, 2014). The first type includes those that involve focusing attention on an external object such as a blank wall, a repeated sound or mantra such as 'Om', an internal sensation such as breathing, or movements such as yoga exercises. In this type of meditation, the meditator also has to monitor their concentration and, if the mind wanders from the object of concentration, to return attention to the object.

This may be contrasted with meditations involving open monitoring in which the meditator simply observes the rising and fading of thoughts, feelings, memories etc. without focusing on them. In other words, there is no object of concentration in open monitoring meditation. Another common type of meditation is the loving kindness meditation (Lippelt, Hommel \& Colzato, 2014). Here the aim is to develop the qualities of love and compassion, first for oneself and then to extend positive feelings more widely, e.g., from self to a friend, then to people who live nearby, to all living beings and then finally to people the meditator dislikes. These and most other types of meditation tend to be done in a quiet setting to minimise distractions.

People meditate for many reasons including improved health and well-being, and/or to understand themselves better or become more aware (Sedlmeier, Eberth, 
Schwartz, Zimmermann, Haarig, Jaeger \& Kunze, 2012). The latter motive includes those who meditate within a religious or spiritual tradition and may extend to achieving transcendent or transpersonal insights (Ekici, Garip \& Van Gordon, 2020), or to achieving enlightenment (Sedlmeier \& Theumer, 2020; Taylor, 2017).

Mindfulness meditation practices have been shown to have a wide range of individual psychological health benefits, including reductions in symptoms of depression and anxiety (Khoury et al., 2013), and improvements in well-being and other mental health measures (Keng, Smoski, \& Robins, 2011; Khoury et al., 2015), cognitive abilities (Chiesa, Calati, \& Serretti, 2011), and in physical health (Keng et al., 2011). Meditation has also been shown to benefit more people than just the individual meditating through increasing the prosocial behaviour of the meditator (Goleman \& Davidson, 2017). In a systematic review, mindfulness as both an intervention and as a personality variable, was linked to prosocial behaviour (Donald, Sahdra, Zanden, Duineveld, Atkins, Marshall \& Ciarrochi, 2019).

A secondary component of this study was to look at the effect, if any, of binaural beats, an auditory phenomenon in which tones of different frequency are presented to each ear simultaneously, usually via headphones. Under this condition what is usually experienced is the creation of a new, third tone, whose frequency is equivalent to the difference between the two tones being played. For example, if the right ear is sent a tone of $200 \mathrm{~Hz}$ and the left ear is sent a tone of $206 \mathrm{~Hz}$, what is experienced is a third tone of $6 \mathrm{~Hz}$ (Oster, 1973) The most consistent finding in a review of the effects of binaural audio was increased feelings of relaxation and reduced feelings of anxiety (Chaleb, Wilpert, Reber \& Fell, 2015).

A small number of studies have suggested that listening to binaural sound at the EEG frequency observed during a deep resting state (between $4 \mathrm{~Hz}$ and $8 \mathrm{~Hz}$ in the range known as theta waves) facilitates meditative states. Jirakittayakorn and Wongsawat, 2017, for example, showed that presenting participants with $6 \mathrm{~Hz}$ binaural audio for 30 minutes evoked theta wave activity in the cortex and parietal regions of their brains and induced a meditative state. As a personal experiment and as part of this study, I included 30 minutes of listening to binaural audio at $6 \mathrm{~Hz}$ in my meditation practice, but in all other respects meditated as usual. I stopped using the binaural audio in my daily practice when this study concluded, however, as it had no effect that I could discern, so this theme is not developed any further in this paper.

My main practice is 90 to 120 minutes a day of what is sometimes called effortless meditation (Russell, n.d.), a type of open monitoring meditation. This approach can be summarised by $10^{\text {th }}$ century Buddhist monk, Tilopa's, 'Six Words', as translated from the Tibetan by McLeod (n.d.): 
Let go of what has passed.

Let go of what may come.

Let go of what is happening now.

Don't try to figure anything out.

Don't try to make anything happen.

Relax, right now, and rest.

As this study aims to explore subjective experiences and their interpretations in a naturalistic setting, a qualitative method is most appropriate. Drawing on the principle of phenomenology, the study of the experience of things themselves, as developed by Edmund Husserl (see, for example, Moran, 1999), this study is concerned with the way things appear to, or are interpreted by, one individual. While Interpretative Phenomenological Analysis (IPA) is useful for exploring interpretations, the double hermeneutic approach cannot be applied when the researcher is the participant. Thematic Analysis (TA) (Braun and Clarke, 2006) has the flexibility to accommodate interpretation of subjective experience by a researcher-participant and is therefore the most suitable method of analysis. TA is a flexible method of analysing text that is largely independent of the theoretical orientation of the researcher. It is a way of identifying themes or patterns in a body of data. The data set for this study was a daily diary of meditation experiences, written as soon as the 90 -minutes of meditation ended. TA was performed on the whole data set in an inductive, data driven, or 'bottom up' process.

The research question that guided this study was: 'What does an experienced meditator experience while meditating?'

\section{Method}

\section{Participant}

The author of this study was the only participant. I describe myself as an experienced meditator having started meditating in 1978 and meditating more frequently and for longer durations since then, until I now meditate for at least 90 minutes a day, every day, and have done so for several years. I have no history of mental health disorders. I recently retired after forty years as a teacher, researcher and practitioner of psychology in higher education. I am not a member of an organisation or religious tradition that has a favoured meditation method. My choice of meditation practice has always been determined by a search for an evidence-based practice that evoked feelings of inner peace and tranquillity, improved well-being, and facilitated the exploration of inner life. My long-term practice is called effortless meditation (Russell, n.d.) and is a type of open monitoring or insight meditation that fulfils these aims. 


\section{Data Collection}

The data gathered in this study was in the form of an unstructured daily meditation diary. A diary is an ideal method for capturing the subjective experience of meditation as it provides an intimate window into the personal world (Ketelle, 2012).

As part of this study, I also kept, and considered including, weekly quantitative scores on measures of happiness and subjective well-being: the Fordyce Emotions Questionnaire (Fordyce, 1988), which provides a score out of 10 for happiness and the Satisfaction with Life Scale (Diener, 1984), which provides a score out of 7 for life satisfaction. However, as these scores all started high, with very little change over the two months of the study, a ceiling effect, I felt that they would add little to the study so I have not included them. More sensitive scales would be needed to show an effect on these factors. The data are available for inspection on request.

\section{Procedure}

For this study I followed my typical practice of meditating for 90 minutes every morning, shortly after waking from sleep. I sat upright on a dining chair in my living room and timed the process using a free phone app, Insight Timer, set to chime a bell-like tone every 30 minutes. The first 60 minutes of the meditation period were with ambient sounds only, consisting mainly of birdsong and distant traffic noise. During the final 30 minutes, binaural audio at a frequency of $6 \mathrm{~Hz}$ was played through headphones, which rendered ambient sounds inaudible.

At the end of the 90 minutes I immediately wrote diary notes of the meditation experience, a process typically taking 15-30 minutes. Included in the notes were comments about thoughts, feelings, memories and anything more unusual, such as experiences I thought of as transcendent because they felt profound or deeply insightful, that arose during the 90 minutes. If anything occurred during the meditation that seemed to relate to the binaural audio, I also added that to the notes. On two occasions I added notes from experiences at other times of the day, if the effects seemed related to the meditation.

\section{Findings}

Inductive TA was performed on this data set to identify themes in the diary notes, with particular emphasis on concepts and observations that were mentioned more frequently. These themes could be observations, feelings, or interpretations.

In summary, these themes were:

Over-arching theme: What is meditation? 


\section{Theme: Is this really meditating?}

Theme: Thinking again - just stop it!

Over-arching theme: Something feels different! Changes in sensations or feelings while meditating

Theme: Becoming more aware of sensations

Theme: Feeling more peaceful and calm

Theme: Feeling happy and contented

Theme: Discomfort or less pleasant feelings

In a theme by itself:

\section{Theme: Unusual or altered states of consciousness}

\section{Over-arching theme: What is meditation?}

Meditating didn't just consist of sitting down and getting on with it. Thoughts or insights arose about the process of meditating itself: what does meditation consist of; when is an experience a meditation and when is it just sitting not doing much; what is a good meditation or a bad meditation and is there even such a thing as a good or bad meditation? These thoughts arose both during the time set aside for meditating and also during the period of reflection and meditation diary writing.

\section{Theme: Is this really meditating?}

Thoughts came up a number of times about what actually constitutes a meditation. They included wondering whether any activity could be described as a type of meditation or whether there is something that sets meditation apart from other activities. The data give a sense that it was not considered enough to simply sit and observe the mind, without expectations, for a while. Looked at retrospectively this is interesting because, if asked directly "What is meditation?" that is exactly what I would say that it is! Somehow, in the moment, that was not considered enough, as though there had to be some sort of change in experience to be considered a meditation at all, never mind a good meditation.

N.B. The diary quotes given below to illustrate the themes also include the number of the day, between 1 and 61, on which the quote was written.

Day 1: In the meditation diary that I have kept for a little over a year, if a meditation involved no difference from the typical pattern of thoughts arising, thoughts fading, periods of no thought and a feeling of being a bit quieter and more relaxed at the end of the meditation than the beginning then I did not write any notes. Today would have been such a day. 
Day 23: Feeling that a meditation with many thoughts arising is wrong in some way or inferior because of a lack of concentration.

Sat with that for a while. Those thoughts changed to thinking that it doesn't matter as long as it's possible to experience awareness. Then I felt more settled.

Day 39: Struggling to find anything to write today. I just sat and thoughts arose now and then with little change over the 90 minutes.

There are suggestions here of some sort of inner contradiction between the prior understanding of what meditation is and the descriptions given in the diary of the experience of meditation. In other words, if my prior view was that the type of meditation I do simply consists of observing the mind without expectations then a meditation consisting of day-to-day thoughts would be as good and as noteworthy as any other. These are the kind of subtle expectations that I wasn't previously aware of, that a meditation diary can help reveal.

There were also thoughts about boundary issues (when am I meditating and when am I not?) and expressions of dissatisfaction with some meditation experiences. These suggest that meditation is engaged in to evoke change or gain deeper understandings, so something different is expected to happen than in other daily activities.

Day 8: I write these notes in the period after the end of the 'meditating' phase. Today it occurs to me that this is part of the overall meditation experience - it is a meditation in its own right as it is a period of quiet reflection before moving on to the tasks of the day (doing the laundry next!). In the moments when I am not writing I experience it in the same way as the more formal meditation, as a peaceful, quiet time, often without thoughts.

Day 39: I can still detect a small wish that there be a different process during meditations than in the rest of my day - an indication of an expectation or attachment.

Day 50: Many thoughts until it gradually changed to drowsiness. It could hardly be called a meditation...

\section{Theme: Thinking again - just stop it!}

Many items were linked to this idea. It reflects the special status given to the process of thinking during meditations. Whether more or fewer thoughts arose than in other daily activities was seen as relevant to the quality of, and satisfaction with, the meditation process.

Day 21: Thoughts, no thoughts, thoughts, no thoughts, all the way through...

Little change from beginning to end. Mind slightly quieter.

There was a feeling of dissatisfaction in the quote from day 21 that does not come across as clearly in the words alone. The data suggest that thoughts are considered something unpleasant to be reduced, or at least less pleasant than having few or no thoughts, and that a 'good' meditation would involve a reduction in the number of thoughts. 
Day 2: The feeling of quiet, calm stillness continued and the periods without thoughts lasted longer.

Day 12: Settled quickly and experienced a long (for me) period with either no thoughts or with just the early hints of thoughts which faded before forming, as soon as they were noticed. It's difficult to estimate times but I'd say this phase lasted at least 20 minutes or so.

There were also reflections on the factors that may have changed the number of thoughts occurring during a meditation. The emphasis was on factors that could potentially reduce the number of thoughts in the moment or in future meditations.

Day 8: I noticed that if I breathe out slowly then pause before breathing in again, no thoughts arise for at least a few seconds.

Day 38: Thoughts also constantly rising and falling, mainly rising when energy levels were higher. Despite there being little difference between this meditation and my usual inner process, it still felt quieter at the end and for a while after.

There was an expectation that meditation would result in a reduction in the number of thoughts that arose, both during the meditation phase and in other aspects of life. Again, this was seen as a desirable outcome of meditation.

Day 13: Throughout the 90 minutes of the meditation, thoughts arose, stayed a while and faded. Almost as soon as one thought faded another arose, with no discernable change throughout. It is more common in my experience for the quiet spaces between thoughts to lengthen, but not today. Sometimes thoughts are like that.

Day 22: About halfway through, thoughts became fewer and the quiet periods lasted longer. The transition from 'noisy' thinking to relative quiet happened quite quickly, over a few seconds. That then persisted, although thoughts didn't entirely quieten, and carried on after the 90 minutes ended.

Day 41: The early part of the meditation was relatively quiet inside. Then, for about quarter of an hour, no thoughts at all that I could discern. Finally, for the remaining 45 minutes and beyond, there was only an occasional very fleeting thought. This is rare. Unprecedented even.

Gratitude!

\section{Over-arching theme: Something feels different! Changes in sensations or feelings while meditating}

This overarching theme is about changes in sensations and feelings. What kind of differences or experiences were considered worth noting? Differences were noted in sensations originating within the body (as distinct from sights, sounds, smells etc. originating in the outside world) and in feelings.

\section{Theme: Becoming more aware of sensations}


During some meditations, body sensations such as itchiness, aching and tingling were experienced more intensely to an extent that was felt to be worth noting. The sense given in these items is that it is usually the increased intensity of the experiences that was worth noting, rather than the specific sensations themselves. Changes in the intensity or the richness of experiences were seen as changes being due to meditating.

Day 1: During the binaural phase I noticed muscles in my back, shoulders, neck and jaw were tighter than usual and so deliberately relaxed them.

Day 2: In the binaural phase I noticed that my body felt as though it was tingling all over. This also lasted for several minutes after the end of the audio.

Day 8: Early in the meditation I noticed that the pain and stiffness in my neck, that I have had for a couple of days, is starting to fade and the sensations intruded less - a small source of pleasure.

Day 49: Increasingly still and quiet with occasional drowsiness. Sensory impressions seem more prominent and intense than usual.

Day 51: Feeling energised. Sensory impressions more intense, from the ringing in my ears to vibrations in the house.

\section{Theme: Feeling more peaceful and calm}

Another group of more commonly noted changes that occurred while meditating were a cluster of feelings such as inner peace, tranquility, calmness and inner quiet. These were attributed to the process of meditation and were experienced to a noteworthy extent.

Day 2: The feeling of quiet, calm stillness continued and the periods without thoughts lasted longer.

Day 48: A quiet, peaceful meditation. A bit drowsy in the second half, without actually dropping off to sleep!

These peaceful feelings were seen as desirable outcomes of meditation to the extent that, achieving such feelings were among the main reasons for engaging in meditation. There is a sense of wanting such experiences to last longer than just during the meditation time. In other words, meditation is being engaged in to gain long term changes in inner peace etc. and not just during the meditation time itself.

Day 5: Again there was a pleasant, calm, peaceful feeling that was deeper after the bin [binaural] phase than the non-b [no audio] phase, and I felt reluctant to start moving again to start other daily routines so I sat for a few minutes appreciating the peaceful feeling before moving to write these notes.

When I experience these peaceful feelings they tend to gradually fade over the course of the next hour as I get into daily routines and disappear completely when I read social media or look at personal finances! 
Day 11: Sometimes my awareness wandered off with thoughts or memories but most of the time it stayed with the present and simply being here. It seemed easier to stay present during the bin [binaural] phase.

With this went a feeling of calm and quiet and I enjoyed staying with that for a while after the audio finished - so simple but wonderful!

[Note added later that day] The feeling of contentment continued to the end of the day.

\section{Theme: Feeling happy and contented}

In some meditations feelings of positive hedonic tone were experienced on a dimension from pleasantness and contentment, through happiness to bliss.

Day 7: A gradual process of inner quietening through both the non-b [no audio] and bin [binaural] phases until the last few minutes of the bin phase. I felt happy for no reason and smiled. Although not a strong feeling, it was very pleasant and continued after the end of the audio. It was a small 'good to be alive' moment.

Again these were attributed to the process of meditation and, as before, there is a sense of wanting such experiences to last longer than just during the meditation time - they are a long term aim. They were at least a partial answer to the question, "why meditate?"

Day 3: A very typical experience all through the meditation until the last few minutes of the binaural phase when I experienced a feeling of happiness that arose for no apparent reason. A thought that popped up at this point was "This is always here, you just need to turn to it."

Thoughts that arose before that were mainly about the dawn chorus audio file that I created immediately before starting meditation. (Today is international dawn chorus day.)

The pleasant, calm happiness continued after the end of the audio.

Day 42: I would have described most of the meditation as pleasantly peaceful - quiet, not too many mundane thoughts popping up. But as it came towards the end, that quality didn't change but it felt blissful. No fireworks. No altered state. Just ordinary, everyday bliss! I sat with it after the time ended because it was such a good feeling, but notes need writing, plants need watering etc...

Day 46: That was wonderful! The whole meditation flowed smoothly and quietly from beginning to end and beyond. Thoughts came and went as usual, and it all felt quiet and peaceful - deeply relaxing. Perhaps it was associated with the greater sense of acceptance I also noticed. Whatever happened (or not) was fine.

\section{Theme: Discomfort or less pleasant feelings}

In some meditations feelings of negative hedonic tone were experienced, including unwanted drowsiness, body aches and restlessness. 
Day 4: I felt slightly drowsy about midway through the bin [binaural] phase so I turned my head from side to side for a few seconds while breathing more deeply and the feeling passed in less than a couple of minutes.

Day 8: I felt the need, later in the non-b [no binaural audio] phase, to stand and move slowly to loosen joints that were aching and uncomfortable (legs and back). I moved slowly and mindfully, trying not to disrupt the feeling of calm presence.

Other such feelings included lack of clarity, distractability and negative feelings about the number of thoughts that arose. As in the previous theme, these feelings were attributed to the process of meditation. Some items indicate that the feeling was not expected, while others were at least not seen as surprising.

Day 33: Unusual sounds from my computer drew attention. So, instead of the usual effortless meditation I began observing the breath, slowing the out breath and pausing at the end of the out breath. I felt a sense of relief during those silent pauses and a releasing of the small tensions I associate with a chattering mind.

Day 38: Trusting the process even when nothing is clear.

Day 50: Many thoughts until it gradually changed to drowsiness. It could hardly be called a meditation...

These were seen as problems that needed solving, rather than something to be accepted. The brief quote for day 38 , for example, refers to confusing thoughts during the meditation giving rise to feeling unclear and that this could be solved by trusting the meditation process.

In a theme by itself:

\section{Theme: Unusual or altered states of consciousness}

Some meditation experiences were outside the usual day-to-day experiences of thoughts, feelings, sensations, memories etc. and their coming and going. This theme includes more unusual changes such as to the sense of identity, or the arising of feelings that were not expected while simply sitting quietly, or of different states of consciousness, not previously experienced.

Day 2: As I began moving after the end of the meditation period, I noticed that I felt taller, and somehow lighter and more spacious. In a way it was a pleasant feeling but in a detached kind of way - a bit hard to describe.

Day 8: Towards the end of the meditation I noticed that I experienced my inner world as a space within which those things of which I am aware appear and disappear. That space is mainly occupied by visual sensations, but when I close my eyes to meditate it seems to become a quieter space. While noticing this experience, the space seemed to expand and become more peaceful.

Day 10: After the audio stopped I moved my hand to the computer to quit the VLC application [for playing audio files]. My hand looked like an external object - something that was different to 'me' for a short while. 
Day 25: Still, quiet, peaceful. Love is here too but is not as clear to me as other aspects.

Overall, such feelings were accepted or regarded as indications of growth or progress. As mentioned above, meditation is engaged in to bring about changes such as greater self-understanding and inner peace, and the experiences in this group are seen to be indications of such changes, and more, taking place.

Day 17: A feeling of spaciousness and timelessness emerged, ironically towards the end of the bin [binaural] phase, although I was only aware that it was near the end because the audio began to fade while that feeling was present.

Day 24: Became aware of an aspect of consciousness - It seems different to day-to-day awareness of the mass of sensory information and memories etc. - free, fluid, detached. It's a bit like a companion but without being separate.

Day 48: A sense of a vast inner space in which things appear when they emerge into conscious awareness, particularly during the first half of the meditation.

Some experiences were so outside normal day-to-day experiences that it was not possible at the time to describe them or put them into words. I could describe such experiences as being transcendent or transpersonal now, while being aware that these words still don't clearly communicate the experience.

Day 37: As I sit, quietly and present, with no thoughts or feelings, there are no words to describe it. No words are adequate or relevant. It just is. Yet here I am writing about it. I can only write because I am not in that conscious place. When I am in that place there is no urge or thought to write.

Day 56: Empty. No-one home. Simply aware. Awareness observing things rather than the 'me' called 'Peter'.

Day 58: It began with simply feeling deep and profound and then moved into a profound sense of infinite inner space

Then came the feeling of a wonderful eternal 'now'. There is nowhere else but here and now.

There is nowhere else to be and nothing else to do - the feeling that this is exactly right.

There was no obvious reason why this meditation should have been like this - it just happens sometimes when one is here and open.

\section{Discussion}

This has been a response to the research question, 'What does an experienced meditator experience while meditating?' When looking over this two-month journal of meditation experiences I was struck by the range of experiences from mundane and trivial to the profound and transcendent. From the outside it would have seemed that every day was very similar, simply someone sitting quietly and still for 90 minutes. The meditation notes, on the other hand, suggest a mix of interested observations, 
curiosity about phenomena and longer term effects, musings on identity, and even reflections on the meaning of life. This difference between inner experience and outer appearance reflects one of the strengths of the personal narrative autoethnography. What were previously inner, personal experiences can now be reflected on by others and compared to their own inner experience.

It would be easy to focus mainly on the unusual or transpersonal experiences in the journal. For those seeking to understand the mind or explore human potential, these are the kinds of experience that seem to throw light onto those issues. And yet it was the simple experience of sitting quietly for a while in the midst of a busy life that was, perhaps, more typical and more relevant.

One of the most useful insights gained from this study relates to expectations and meditation. Before the study I would have said that I had few expectations about what should happen while meditating. However, the theme, 'Is this really meditating?' reveals the opposite to be the case. I clearly expected meditation to evoke experiences different from simply sitting quietly. This was a valuable insight and has led to changes in how I approach and think about meditation since making that observation. The insight might not have been identified without having written a detailed meditation journal. Experience alone, without subsequent reflection and analysis, may not be enough for a meditation practice to develop.

Concerning some of the experiences in the theme, 'Unusual or altered states of consciousness' it is clear that these were unexpected and mysterious to some extent. However, since ending the meditation phase of this study I came across a description of altered states that are known in Buddhism as 'jhanas' (Brasington, 2015). Some of the experiences described above, particularly experiences of unexpected happiness, inner peace and equanimity, and also of inner spaciousness, could be seen as due to entering one or more of the eight jhanas, as they are consistent with traditional descriptions of those states. While the eight jhanas are usually described as manifesting in a specific sequence, Brasington allows for the possibility of entering them without planning or going through a specific sequence of stages.

The paucity of first-person accounts of meditation experiences makes comparison with comparable studies impossible. Woollacott (2016) makes the point:

Scientific research on meditation may be able to identify which neurons are activated in meditative states, but this is insufficient. Within our studies, we need to include the first-person perspective and to examine heightened awareness during meditation.

The present study makes a contribution to this gap in the research and provides just such a first-person perspective on the meditation experience. 
In the Introduction I made the point that this study was something that could be done during the unusual circumstances of the first covid-19 lockdown that was in place in England during 2020. I found that both carrying out this study and meditation itself had beneficial effects. It has been an interesting and engaging experience for me that I hope others also find useful. Being able to both carry out and write about meditation experiences, in the hope of helping others, also gave me a feeling of being part of the culture of meditators, of reaching out and connecting with others at a time of being physically alone, not seeing or talking to others except through virtual media.

\section{Limitations}

The most obvious limitation is that this is a study by and of just one meditator. Those who discuss their meditation experiences, in group meditation settings for example, will be aware of the variety of experiences that are possible. Wider study with more participants will give a better idea of the range of possibilities, even within just one type of meditation.

It is important to remember that this is not a roadmap of the meditation process and nor are anyone else's meditation experiences. Those new to meditation may find it useful to note that experiences can vary widely. In fact it is considered potentially misleading in some meditation circles to talk about meditation experiences in case it encourages unhelpful expectations.

\section{Further research}

The most obvious need is for more studies of the subjective experience of meditation and not just through the narrow lens of psychometric questionnaires. The subjective experience is a crucial aspect of meditation and yet, as mentioned above, one of the least studied. Meditation is increasingly recommended for those experiencing anxiety, depression, stress and other mental health issues. To be confident that it can be recommended safely requires a more thorough understanding of what people can expect to experience while meditating. Clinicians need to know that not all meditation experiences are positive, for example.

It would also be worth exploring further those experiences described here as unusual or altered states of consciousness, within the context of the experiences described within Buddhism as the jhanas (Brasington, 2015). This may be a useful framework within which to study some of the less well understood meditation experiences.

\section{Acknowledgements}

I would like to extend grateful thanks to Dr Helen Eccles and Dr John Hockey for helpful feedback on the first draft of this paper. 


\section{Compliance with Ethical Standards}

Conflict of Interest The author declares that he has no financial conflicts of interest and no ties to any religious or spiritual tradition.

Ethical Approval As a retired academic with no institutional affiliation, I no longer have access to an ethics review process. However, I would like to reassure readers that I treated myself ethically and followed ethical guidelines throughout the research process (Wester, 2011). All procedures were in accordance with the code of ethics of the British Psychological Society (2018).

Informed Consent Informed consent is not an issue for this type of study.

\section{References}

Brasington, L. (2015). Right concentration: A practical guide to the jhanas. Boston and London: Shambhala.

Braun, V. \& Clarke, V. (2006). Using thematic analysis in psychology. Qualitative Research in Psychology, 3(2), 77-101. doi: 10.1191/1478088706qp063oa

British Psychological Society (2018). Code of Ethics and Conduct (2018). Leicester: British Psychological Society. Retrieved 21 October, 2020 from https://www.bps.org.uk/news-andpolicy/bps-code-ethics-and-conduct

Chaleb, L., Wilpert, E. C., Reber, T. P., \& Fell, J. (2015). Auditory beat stimulation and its effects on cognition and mood states. Frontiers in Psychiatry, 6(70) https://doi.org/10.3389/fpsyt.2015.00070

Chiesa, A., Calati, R., \& Serretti, A. (2011). Does mindfulness training improve cognitive abilities? A systematic review of neuropsychological findings. Clinical Psychology Review, 31, 449-464. https://doi.org/10.1016/j.cpr.2010.11.003

Diener, E. (1984). Subjective well-being. Psychological Bulletin, 95, 542-575.

Donald, J. N., Sahdra, B. K., Zanden, B. v., Duineveld, J. J., Atkins, P. W. B., Marshall, S. L. \& Ciarrochi, J. (2019). Does your mindfulness benefit others? A systematic review and meta-analysis of the link between mindfulness and prosocial behaviour. British Journal of Psychology, 110, 101-125.

Ekici, Ç., Garip, G., \& Van Gordon, W. (2020). The lived experiences of experienced Vipassana Mahasi meditators: An interpretative phenomenological analysis. Mindfulness 11, 140-152. https://doi.org/10.1007/s12671-018-1063-4

Ellis, C., Adams, T. E. \& Bochner, A. P. (2011). Autoethnography: An overview. Forum: Qualitative Social Research, 12(1), Article 10. http://nbn-resolving.de/urn:nbn:de:0114-fqs1101108

Emergent Phenomenological Research Consortium (n.d.). Retrieved 18 March, 2020 from https:// theeprc.org/

Fordyce, M. W. (1988). A review of research on the happiness measures: a sixty second index of happiness and mental health. Social Indicators Research, 20, 355-381.

Goleman, D. \& Davidson, R. J. (2017). Altered traits: Science reveals how meditation changes your mind, brain, and body. New York: Avery.

Isbel, B., Sysak, T. \& Summers, M.J. (2020). A qualitative examination of the developmental trajectory of learning mindfulness across an 8-week program. Mindfulness 11, 2741-2754. https://doi.org/10.1007/s12671-020-01484-6

Jirakittayakorn, N. \& Wongsawat, Y. (2017). Brain responses to a 6-Hz binaural beat: effects on general theta rhythm and frontal midline theta activity. Frontiers in Neuroscience, 11, 365. https://doi.org/10.3389/fnins.2017.00365 
Keng, S-L., Smoski, M.J. \& Robins, C.J. (2011). Effects of mindfulness on psychological health: A review of empirical studies. Clinical Psychology Review, 31(6), 1041-1056.

Ketelle, D. (2012). Talking to myself: diary as a record of life process. International Journal of Humanities and Social Science, 2(7), 34-40.

Khoury, B., Lecomte, T., Fortin, G., Masse, M., Therien, P., Bouchard, V., . . Hofmann, S. G. (2013). Mindfulness-based therapy: A comprehensive meta-analysis. Clinical Psychology Review, 33, 763-771. https://doi.org/10.1016/j.cpr.2013.05.005

Khoury, B., Sharma, M., Rush, S. E., \& Fournier, C. (2015). Mindfulness-based stress reduction for healthy individuals: A meta-analysis. Journal of Psychosomatic Research, 78, 519-528. https:// doi.org/10.1016/j.jpsychores.2015.03.009

Kjellgren, A. \& Taylor, S. (2008). Mapping Zazen meditation as a developmental process: Exploring the experiences of experienced and inexperienced meditators. The Journal of Transpersonal Psychology, 40(2), 224-250.

Lindahl, J. R., Fisher, N. E., Cooper, D. J., Rosen, R. K. \& Britton, W. B. (2017). The varieties of contemplative experience: A mixed-methods study of meditation-related challenges in Western Buddhists. PLoS ONE 12(5): e0176239. https://doi. org/10.1371/journal.pone.0176239

Lades, L. K., Laffan, K., Daly, M. \& Delaney, L. (2020). Daily emotional well-being during the COVID-19 pandemic. British Journal of Health Psychology, https://doi.org/10.1111/bjhp.12450 [Epub ahead of print].

Lippelt, D.P., Hommel, B. \& Colzato, L. S. (2014). Focused attention, open monitoring and loving kindness meditation: effects on attention, conflict monitoring, and creativity - A review. Frontiers in Psychology, 5(5), 1-5. https://doi: 10.3389/fpsyg.2014.01083

McLeod, K. (n.d.). Mahamudra - Tilopa's Six Words. Unfettered Mind: Pragmatic Buddhism. Retrieved 18 March, 2020 from http://unfetteredmind.org/tilopas-advice/

Moran, D. (1999). Introduction to Phenomenology. London: Routledge. https://doi. org/10.4324/9780203196632

Oster, G. (1973). Auditory beats in the brain. Scientific American, 229(4), 94-102. doi: 10.1038/ scientificamerican1073-94.

Roth, W-M. (2003). “If Somebody's with Something Every Day They've Gotta Learn SomethingOr They're Just Out to Lunch": The Dialectics of Ethnography as a Way of Being. Forum: Qualitative Social Research, 4(3). doi: http://dx.doi.org/10.17169/fqs-4.3.690

Russell, P. (n.d.). Effortless meditation. Peter Russell. Retrieved 18 March, 2020 from https://www. peterrussell.com/Odds/EffortlessMeditationCL.pdf

Sedlmeier, P., Eberth, J., Schwartz, M., Zimmermann, D., Haarig, F., Jaeger, S. \& Kunze, S. (2012). The psychological effects of meditation: a meta-analysis. Psychological Bulletin, 138(6), 1139-1171.

Sedlmeier, P. \& Theumer, J. (2020). Why do people begin to meditate and why do they continue? Mindfulness, 11, 1527-1545. https://doi.org/10.1007/s12671-020-01367-w

Taylor, S. (2017). The Leap: The Psychology of Spiritual Awakening. London: Hay House.

Thomas, J. W. \& Cohen, M. (2014). A methodological review of meditation research. Frontiers in Psychiatry, 5(74). doi: 10.3389/fpsyt.2014.00074

Walsh, R. (1977). Initial meditative experiences: Part 1. The Journal of Transpersonal Psychology, 9(2), 151-192.

Wester, K. L. (2011). Publishing ethical research: A step-by-step overview. Journal of Counseling and Development, 89(3), 301-307. doi: 10.1002/j.1556-6678.2011.tb00093.x

Woollacott, M. (2016). Science and meditation: Integrating a first-person experience into the scientific process. Marjorie Woollacott. Retrieved 1 March 2021 from https://marjoriewoollacott.com/2016/01/ science-and-meditation-integrating-a-first-person-experience-into-the-scientific-process/ 
